\title{
Konsep Kafa'ah: Studi Pandangan Habaib di Kabupaten Jember
}

\author{
Aba Fahmi Roby ${ }^{1}$ \\ ${ }^{1}$ Fakultas Syariah, IAIN Jember. E-mail: jr8228144@gmail.com
}

\begin{tabular}{|c|c|}
\hline Article & Abstract \\
\hline $\begin{array}{l}\text { How to cite: } \\
\text { Aba Fahmi Roby, 'Konsep } \\
\text { Kafa'ah (Studi } \\
\text { Pandangan Habaib di } \\
\text { Kabupaten Jember)' Vol. } \\
1 \text { No. } 3 \text { Rechtenstudent } \\
\text { Journal Fakultas Syariah } \\
\text { IAIN Jember. } \\
\text { Histori artikel: } \\
\text { Submit } 7 \text { September 2020; } \\
\text { Diterima } 19 \text { November } \\
\text { 2020; Diterbitkan } 7 \\
\text { Desember 2020. } \\
\text { ISSN: } \\
\text { 2723-0406 (media cetak) }\end{array}$ & 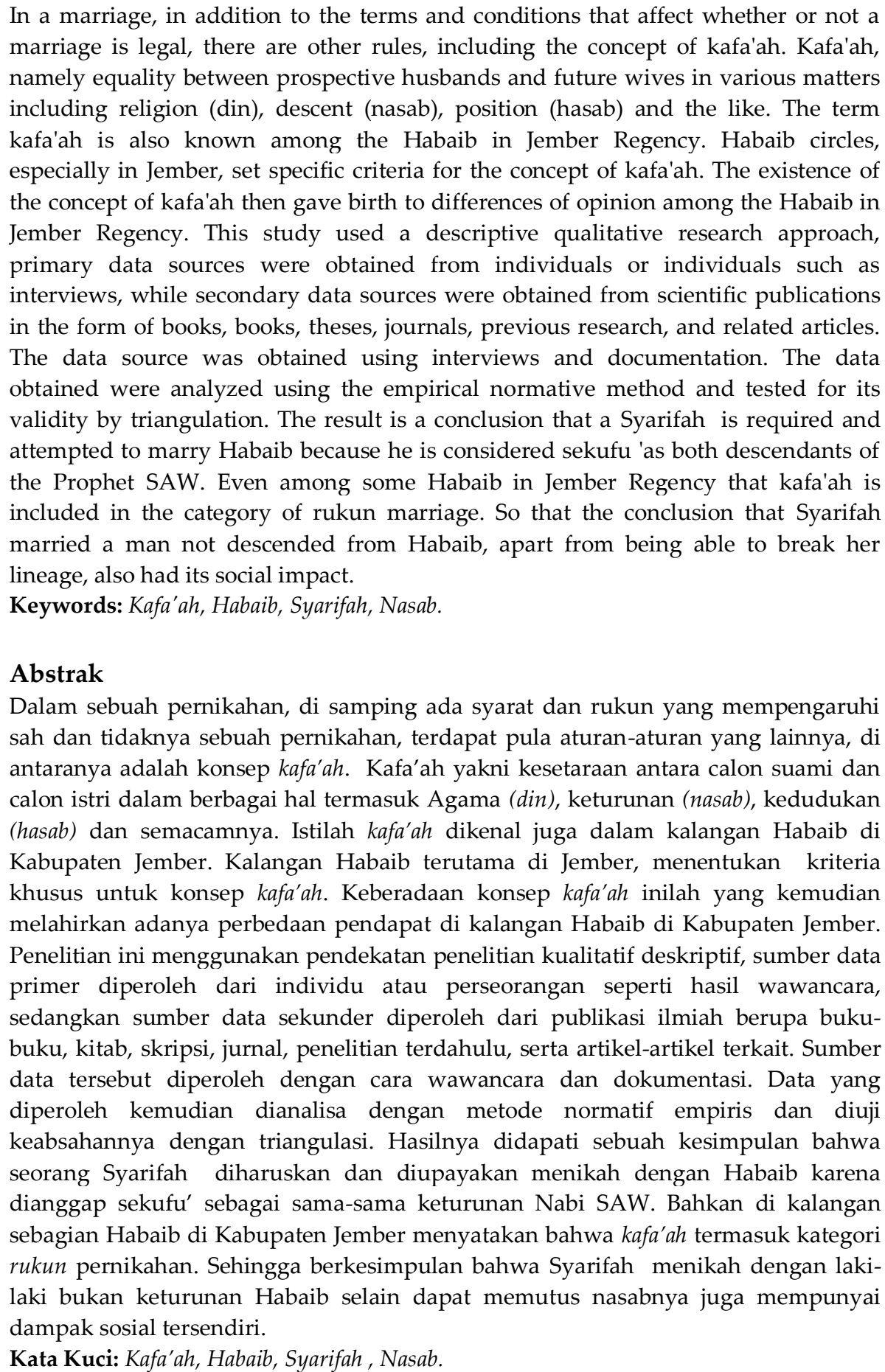 \\
\hline
\end{tabular}




\section{Pendahuluan}

Manusia diciptakan oleh Allah secara berpasang-pasang, tak terkecuali manusia sebagai makhluk yang paling mulia, dengan kata lain, berpasangan merupakan fitrah manusia untuk melestarikan keturunan guna memerankan diri sebagai khalifah di bumi. Karena itu agama mensyariatkan dijalinnya pertemuan antara pria dan wanita dalam ikatan suci yang dinamakan "Pernikahan". ${ }^{1}$

Kata nikah berasal dari bahasa arab " $ح$ " yang menurut bahasa artinya mengumpulkan, memasukan, dan digunakan dalam arti bersetubuh (watha'). Kata nikah sendiri juga sering digunakan untuk arti persetubuhan (coitus), juga untuk akad nikah. Nikah menurut bahasa mempunyai arti yang sebenarnya (arti hakikat) dan arti kiasan (arti majazi). Arti sebenarnya dari kata nikah dalam bahasa arab adalah "dham" yang berarti "menghimpit", "menindih" atau "berkumpul", sedang arti kiasannya adalah "watha'" yang berarti "setubuh" atau "akad" yang berarti mengadakan perjanjian pernikahan.

Pada umumnya nikah dalam arti majazi inilah yang banyak dipergunakan dalam bahasa sehari-hari. Arti nikah yang sebenarnya jarang digunakan. Sedangkan dalam bahasa Indonesia, perkwinan berasal dari kata kawin yang menurut bahasa artinya membentuk keluarga dengan lawan jenis, melakukan hubungan kelamin atau bersetubuh. ${ }^{2}$ Menurut UU NO.1 Tahun 1947 tentang Perkawinan pasal 1 bahwa: "Perkawinan adalah ikatan lahir batin antara seorang pria dan seorang wanita sebagai suami istri dengan tujuan membentuk keluarga atau rumah tangga yang bahagia dan kekal berdasarkan Ketuhanan Yang Maha Esa." 3 Disamping definisi dalam Undang-Undang No 1 Tahun 1974 di atas, dalam kompilasi Hukum Islam Indonesia juga didapati definisi yang secara redaksi agak berbeda, namun pada hakekatnya sejalan dengan maksud Undang-Undang. Perkawinan menurut Islam adalah pernikahan, yaitu akad yang sangat kuat atau mitsaqon gholizhan untuk mentaati perintah Allah dan melaksanakannya merupakan ibadah.

Hal itu sesungguhnya yang merupakan tujuan utama disyari'atkannya pernikahan dalam Islam. Suasana kehidupan yang dituju oleh pernikahan serupa itu akan dicapai dengan mudah apabila pernikahan dibangun atas dasar yang kokoh, antara suami dan istri ada kafä'ah (keserasian). Kafa'ah adalah kesamaan dan keserupaan, sedangkan kufu adalah orang serupa dan sepadan. ${ }^{4}$ Dalam defiinisi lain dikemukakan kafa'ah adalah keseimbangan dan keserasian antara calon istri dan suami sehingga masing-masing calon tidak merasa berat untuk melangsungkan perkawian. ${ }^{5}$

Maksud dari kafa'ah dalam pernikahan adalah bahwa suami hanya sekufu bagi istrinya, artinya dia memiliki kedudukan yang sama dan sepadan dengan istrinya dalam hal tingkatan sosial, moral, dan ekonomi. Tidak diragukan bahwa semakin sama kedudukan laki-laki dengan kedudukan perempuan, maka keberhasilan hidup suami-istri semakin terjamin dan semakin terpelihara dari kegagalan. Setingkat dalam perkawinan, antara laki-laki dan perempuan ada lima sifat, yaitu menurut dua ibuk-bapak.

${ }^{1}$ https://islam.nu.or.id/post/read/107374/menikah-adalah-fitrah-manusia diakses pada tanggal 27 Oktober 2019, pada jam 21.12 WIB.

2Busriyanti, Figh Munakahat, (Jember : STAIN Jember Press, 2013), hlm 3-5.

${ }^{3}$ Tim Citra Umbara, Undang-Undang no 1 Tahun 1974 tentang Perkawinan dan Kompilasi Hukum Islam (Bandung : CV Nuansa Auliya, 2015), hlm 73.

${ }^{4}$ Sayyid Sabiq, Fiqih Sunnah 3, (Jakarta: Pena Pundi Aksara, 2013), hlm 397.

${ }^{5}$ Busriyanti., Fikih Munakaht, hlm 49. 
1. Agama.

2. Merdeka atau hamba.

3. Perusahaan.

4. Kekayaan.

5. Kesejahteraan.

Kufu' ini tidak menjadi syarat bagi perkawinan, tetapi jika tidak dengan keridhaan masing-masing, boleh yang lain memaksakan pernikahan itu dengan beralasan tidak kufu' (setingkat). Pendapat yang lebih kuat ditinjau dari alasannya, kufu' itu hanya berlaku mengenai keagamaan, baik mengenai pokok agama, seperti Islam dan bukan Islam, maupun kesempurnaannya, seperti orang yang baik (taat), ia tidak sekufu dengan orang yang jahat dan orang yang tidak taat. ${ }^{6}$

Istilah kafa'ah dikenal juga dalam kalangan Habaib di Kabupaten Jember. Kalangan Habaib menentukan kriteria khusus untuk memandang seseorang layak untuk mendampingi hidup putrinya kelak dalam bingkai pernikahan. Kelayakan ini menjadi tolak ukur sekufu' tidaknya orang tersebut dengan putrinya. Dalam penarapan konsep kafa'ah di kalangan Habaib di Kabupaten Jember, dalam hal kafa'ah ada sebagian Habaib yang berpendapat bahwa dalam hal kafa'ah masuk dalam rukun daripada sebuah pernikahan, dan ada juga yang berpendapat bahwa kafa'ah hanya sebatas keafdholan pernikahan saja, yang tentunya perihal tersebut selaras dengan kalangan ulama fikih yang dianut masyarakat pada umumnya.

\section{Rumusan Masalah}

Adapun rumusan masalah dalam penelitian ini adalah:

1. Bagaimana pandangan Habaib perihal relevansi kafa'ah dalam upaya pembentukan keluarga sakinah di Kabupaten Jember?

2. Bagaimana pandangan Habaib terhadap perkawinan wanita syarifah dengan ahwal dalam upaya pembentukan Keluarga Sakinah?

\section{Metode Penelitian}

Penelitian ini adalah penelitian kualitatif deskriptif, sumber data primer diperoleh dari individu atau perseorangan seperti hasil wawancara, sedangkan sumber data sekunder berupa publikasi ilmiah berupa buku-buku, kitab, skripsi journal, dan artikel-artikel yang terkait dengan judul penelitian si peneliti. ${ }^{7}$ Sumber data tersebut diperoleh dengan cara, wawancara dan dokumentasi. Data yang diperoleh kemudian dianalisa dengan metode Normatif empiris dan diuji keabsahannya dengan triangulasi. Metode penelitian pada dasarnya merupakan cara ilmiah untuk mendapatkan data dengan tujuan dan kegunaan tertentu. ${ }^{8}$

\section{Hasil dan Pembahasan}

\section{Sejarah Habaib di Kabupaten Jember}

Sejarah awal kedatangan Habaib di Kabupaten Jember dipelopori Oleh Mbah Shidiq atau KH. Muhammad Shidiq. Beliau lahir tahun 1453 (1854 M) di pedukuhan Punjulsari Desa Waru Gunung Kecamatan Lasem Kabupaten Rembang Jawa Tengah, dan meninggal di turbah

${ }^{6}$ Rasjid Sulaiman, Fiqh Islam, (Jakarta: Kurnia Esa, 1984)., hlm 404-405.

7Sugiono, Metodologi Penelitian Kuantittif dan Kualitatif, Bandung: (Alfa Beta 2014), hlm 23.

${ }^{8}$ Sugiyono, Metode Penelitian Kuantitatif, Kualitatif Dan RED, (Bandung: Alfabet, 2009), hlm 2.

\section{5}


Condro Kabupaten Jember pada hari Ahad Pahing jam 17.40, tanggal 2 Ramadhan 1533 H (9 Desember $1934 \mathrm{M}$ ) pada usia 80 tahun. Mbah Shidiq atau KH. Muhammad Shidiq menurut garis nasab, beliau keturunan Sayyid Abdurrachman alias Mbah Sambu yang berasal dari Keraton Mangkunegaran Solo. Hal ini diungkapkan oleh cicit Mbah Shidiq, KH. Muhammad Balya Firjon Barlaman. ${ }^{9}$

Menurut catatan KH. Achmad Qusyairi yang mengutip dari Syajaroh milik Habib Achmad bin Habib Sahal Basyaiban (Pasuruan), menerangkan tentang Mbah Sambu beliu adalah Al-Sayyid Abdurrachman. Dan Syajaroh tersebut diperkuat oleh catatan milik Sayyid Alibin Ja'far bin Syech As-Segaff. Yang mana catatan milik Sayyid Ali ini ditulis oleh Al-Habib Abdurrachman bin Muhammad bin Husein. Mbah Sambu atau Al-Sayyid Abdurrachman Basyaiban adalah keturunan langsung yang ke-27 dari Rasulullah SAW. Gus Firjon menuturkan bahwa Mbah Shidiq atau KH. Muhammad Shidiq termasuk golongan Habaib yang silsilahnya sebagai berikut :

1. KH. Muhammad Shidiq

2. Bin Raden Pangeran Mas Sayyid KH. Abdullah

3. Bin Raden Pangeran Sayyid KH. Sholeh

4. Bin Sayyid KH. Asy'ari

5. Bin Sayyid KH. Muhammad Adro'i

1. Bin Sayyid KH. Yusuf

2. Bin Sayyid Abdurrachan

3. Bin Sayyid Muhammad Hasyim

4. Bin Sayyid abdurrachman Basyaiban

5. Bin Sayyid Abdullah

6. Bin Sayyid Umar

7. Bin Sayyid Muhammad

8. Bin Sayyid Achmad

9. Bin Sayyid Abu Bakar Basyaiban

10. Bin Sayyid Muhammad Asy'adullah

11. Bin Sayyid Hasan At-Taromi

12. Bin Sayyid Ali

13. Bin Sayyid Muhammad Al-Faqih Muqodda

14. Bin Sayyid Ali

15. Bin Sayyid Muhammad Shohibi Mirbat

16. Bin Sayyid Ali Kholiq Qosim

17. Bin Sayyid Alwi

18. Bin Sayyid Muhammad

19. Bin Sayyid Alwi

20. Bin Sayyid Abdullah Ubaidillah

21. Bin Sayyid Ahmad Al-Muhajir

22. Bin Sayyid 'Isa An-Naqib

23. Bin Sayyid Muhammad An-Naqib

24. Bin Sayyid Ali Al-`Uraidi

25. Bin Sayyid Ja'far Ash-Shodiq

${ }^{9}$ Firjon, Wawancara, Desa Talang Sari Kab. Jember, 26 Desember 2019. 
26. Bin Sayyid Muhammad Al-Baqier

27. Bin Sayyid Ali Zainal Abidin

28. Bin Sayyidina Husein

29. Binti Fatimah Az-Zahroh

Bin Rosulullah Muhammad SAW.

\section{Pandangan Habaib Perihal Relevansi Kafa'ah dengan Keluarga Sakinah dalam Upaya Pembentukan Keluarga Sakinah di Kabupaten Jember.}

Untuk menjaga keserasian dan keseimbangan dalam rumah tangga antara suami dan istri, Islam mengenalkan konsep kafâ'ah sebagai solusi pencapaian rumah tangga yang harmonis, karena kafâ'ah dalam pernikahan akan mendatangkan keluarga yang sakinah, mawaddah dan rahmah. Kafấah dalam arti bahwa istri harus pandai melengkapi segala kekurangan suami, begitu juga sebaliknya, sehingga kehidupan rumah tangga dapat dibina bersama atas dasar saling terbuka, saling menghormati, saling menghargai, saling menjaga hak dan kewajiban masing-masing, serta menjaga peran dalam rumah tangga. ${ }^{10}$

Hal tersebut diungkapkan oleh Habib Fahmi beliau mengatakan bahwa: ${ }^{11}$

“Kafa'ah dengan Keluarga Sakinah Hubungannya adalah saling ada keterkaitan, ketika kafa'ah dengan keluarga sakinah dipahami bahwa kedua saling berkaitan. Yang kafa'ah sendiri bermakna kesetaraan dan keluarga sakinah ialah keluarga yang di dalamnya penuh keharmonisan. Maka mereka akan merasakan sebuah kehidupan yang di dalamnya berupa ketenangan, ketentraman, keteguhan hati, dan memiliki cinta dan kasih sayang. Unsur cinta dan kasih sayang di sini memang harus ada untuk saling melengkapi dengan tujuan saling membahagiakan. Dan kafa'ah di sini termasuk rukun pernikahan."

Maksud dari Habib Fahmi ialah relevansi keduanya sangatlah saling memberikan pengaruh yang signifikan, karena kafa'ah sendiri yang berarti kesetaraan dan sakinah adalah tentang keharmonisan, keduanya sangatlah perlu karena di dalam pernikahan harus ada unsur kesetaraan, cinta dan kasih sayang dengan tujuan dapat merajut sebuah keharmonisan.

Hal ini juga diungkapkan oleh habib Abu Bakar, beliau mengungkapkan, bahwa: ${ }^{12}$

"Kafa'ah dengan Keluarga Sakinah tidak bisa dilepaskan, karena dalam kajian-kajian fikih klasik sendiri adalah sebuah keafdholan atau sebuah keutamaan dalam merajut sebuah pernikahan. Karena akan berdampak pada sebuah keharmonisan di dalam sebuah keluarga. Dan juga mkafa'ah di sini termasuk rukun pernikahan."

Maksud dari Habib Abu Bakar ialah relevansi keduanya sangatlah penting dan berpengaruh, keutamaan dalam sebuah pernikahan, karena semua akan berdampak kepada masa depan dalam berumah tangga.

Hal serupa dijelaskan oleh Habib Firjon, beliau menjelaskan, bahwa: ${ }^{13}$

“Kafa' ah dan Keluarga Sakinah faktor yang sangat penting, di mana diperlukan kafa'ah agar imbang menuju keluarga yang sakinah, yang apabila di antara keduanya tidak sesuai dengan sifat-sifat kafa'ah dikhawatirkan akan mengakibatkan sebuah keluarga

\footnotetext{
${ }^{10}$ Asrizal, "Relevansi Kafâ'ah terhadap Keharmonisan Rumah Tangga Perspektif Normatif dan Yuridis", Al-Ahwal, 1,( Januari, 2015), 72.

11Fahmi, Wawancara, Desa Rambi Puji Kab. Jember, 13 September 2019.

${ }^{12} \mathrm{Abu}$ Bakar, Wawancara, Desa Balung Kab. Jember, 19 September 2019.

${ }^{13}$ Firjon, Wawancara, Desa Talang Sari Kab. Jember, 26 Desember 2019.
} 
yang tidak akan harmonis atau tidak sakinah, dalam hal ini wali tidak boleh sewenangwenang dalam pernikahan"

Maksud dari Habib Firjon ialah relevansi keduanya sangatlah penting. Serasi dan harmonis dapat memupuk sebuah kesejahteraan dalam sebuah pernikahan, yang di dalamnya wali tidak boleh bertindak sewenang-wenang.

Hal serupa juga diterangkan oleh Habib Muhammad, beliau menjelaskan, bahwa: ${ }^{14}$

“Kafa'ah dan keluarga sakinah jelas ada keterkaitan yang khusus, di mana kafa'ah di sini adalah ibarat sebuah petunjuk arah atau peta yang sifatnya peta adalah menunjukan jalan ke tempat yang dituju. Kafa'ah sangatlah penting dalam mencapai keluarga sakinah, karena dikatakan keluarga sakinah ialah keluarga yang harmonis dan terletak sebuah keserasian antara keduanya."

Maksud dari Habib Muhammad ialah keterkaitan antara keduanya sangatlah signifikan. Di mana keduanya diharapkan dapat menciptakan keluarga yang harmonis dan menemukan keserasian nantinya.

Dari hasil wawancara maka dapat menarik kesimpulan bahwa relevansi kafa'ah dengan keluarga sakinah adalah faktor yang sangat penting dan saling berkaitan antara kafa'ah dengan keluarga sakinah, karena kafa'ah dalam sebuah pernikahan akan mendatangkan keluarga yang sakinah, mawaddah dan rahmah. Kafa'ah dalam arti kesetaraan antara keduanya, begitu juga keluarga sakinah, kehidupan rumah tangga yang di dalamnya atas terdapat unsur saling menghormati, saling menghargai, saling menjaga hak dan kewajiban masing-masing, serta menjaga peran dalam rumah tangga. Hal yang perlu diingat bahwa pengertian pernikahan bukan semata-mata kesenangan manusiawi saja, tetapi juga sebagai jalan untuk membangun kehidupan yang sejahtera dan harmonis, baik secara dzahir maupun batin serta menjaga keselamatan agama dan nilai-nilai moral dan akhlak bagi setiap individu dalam menjalani kehidupan, inilah yang menjadi penting.

\section{Pandangan Habaib Terhadap Perkawinan Wanita Syarifah dengan Ahwal dalam Upaya Pembentukan Keluarga Sakinah}

Menurut UU No.1 Tahun 1947 Tentang Perkawinan pasal 1 bahwa: Perkawinan adalah ikatan lahir batin antara seorang pria dan seorang wanita sebagai suami istri dengan tujuan membentuk keluarga atau rumah tangga yang bahagia dan kekal berdasarkan Ketuhanan Yang Maha Esa. ${ }^{15}$

Perihal tersebut diungkapkan oleh Habib Fahmi beliau mengatakan bahwa: ${ }^{16}$

"Pernikahan adalah sebuah bentuk ritual suci yang di dalamnya ada sebuah akad yang sangat kuat untuk mentaati perintah-Nya. Menjaga dan melindungi kelangsungan nasab-keturunan yang baik, tidaklah serta merta identik dengan sebuah kesombongan dan kecongkakan. Semua itu adalah sebuah amanah yang diemban kepada kita kalangan Habaib. Dengan perihal tersebut, maka Syarifah diharuskan menikah dengan Habib karena termasuk dalam syarat pernikahan, dengan alasan menjaga kemuliaan garis keturunan kepada Nabi Muhammad SAW. Maka dari itu apabila menemukan atau

\footnotetext{
${ }^{14}$ Muhammad, Wawancara, Desa Tegal Besar Kab. Jember, 21 November 2019.

15 Tim Citra Umbara, Undang-Undang no 1 Tahun 1974 tentang Perkawinan dan Kompilasi Hukum Islam, hlm 73.

16Fahmi, Wawancara, Desa Rambi Puji Kab. Jember, 13September 2019
} 
mengetahui syarifah nikah dengan orang ahwal maka garis keturunan yang suci kepada Nabi akan putus ketika syarifah tersebut mempunyai anak."

Maksud dari Habib Fahmi ini adalah diharuskannya seorang Syarifah menikah dengan Habib yang garis keturunan atau silsilahnya sambung kepada Rasulullah SAW, dengan tujuan menjaga garis keturunan yang suci. Berlaku sebaliknya, apabila seorang syarifah nikah dengan seorang ahwal yang garis keturunannya tidak sambung dengan Rasulullah, maka sama halnya seorang syarifah tersebut memutus garis keturunan atau silsilah suci yang sambung dengan Rasulullah SAW.

Perihal tersebut diungkapkan juga oleh Habib Firjon menjelaskan bahwa: ${ }^{17}$

"Pernikahan adalah sebuah akad yang sangat kuat atau mitsaqon gholizhan untuk mentaati perintah Allah. Pada dasarnya manusia di hadapan Allah swt adalah hal yang jelas dan pasti. Dan bahwa kemuliaan seseorang di hadapan Allah swt adalah karena sebuah ketaqwaanya kepada Allah semata, itupun sudah pasti dan telah diketahui secara luas dan umum. Dari mulai yang kaya dengan yang miskin, yang normal dengan yang tidak normal, yang sayyid dengan yang bukan sayyid, semuanya mempunyai kewajiban menyembah dan beribadah kepada Allah SWT. Namun itu tak berarti karunia Allah sekaligus sebagai amanah kepada seseorang berupa pangkat, harta kekayaan, kekuasaan, kebangsawanan, atau nasab tidak lantas dinafikan begitu saja, toh semuanya itu adalah pemberian Allah SWT. Dalam tersebut maka perlu diupayakan kepada syarifah yang hendak menikah untuk melihat dan mencari tahu apakah orang yang hendak dinikahinya itu dari golongannya atau dari yang sama garis keturunannya. Semua itu bertujuan menjaga kesucian garis keturunan yang bersambung kepada Rasulullah SAW. Maka dari itu apabila mengetahui Syarifah nikah dengan Orang Ahwal maka semua itu akan berdampak kepada anaknya nanti."

Maksud dari Habib Firjon ini adalah perlunya diupayakan terhadap Syarifah yang hendak menikah, agar terlebih dulu melihat siapa yang hendak menikahinya, dari golongan yang sama atau sama garis keturunannya. Karena semua akan berakibat dan berdampak kepada keturunan selanjutnya yang apabila seorang Syarifah menikah dengan Ahwal.

Perihal tersebut diungkapkan oleh Habib Muhammad, beliau mengatakan bahwa: ${ }^{18}$

"Pernikahan adalah sebuah ikatan yang sangat suci dan harus dipatuhi apapun yang sudah menjadi aturan di dalam nya. Menjaga garis keturunan yang sambung kepada Nabi Muhammad SAW adalah sebuah amanah dan taggung jawab yang begitu berat, yang dalam sisi lain ada sebuah kebanggaan tersendiri. Namun semua itu tidak patut disombongkan karena semua itu adalah pemberian Allah SWT, sekaligus amanah yang dititipkan kepada para Habaib dan Syarifah. Maka dari itu, ketika menjawab sebuah realita yang ada, apabila mengetahui Syarifah nikah dengan orang ahwal maka garis keturunan yang sambung kepada Rasulullah akan putus ketika Syarifah tersebut mempunyai anak."

Maksud dari Habib Muhammad ini adalah pernikahan seorang syarifah harus sangat dijaga, karena sama halnya menjaga dan melestarikan keturunan yang suci yang sambung dengan Rasulullah SAW karena apabila mengetahui Syarifah nikah dengan Orang Ahwal maka garis keturunan yang sambung kepada Rasulullah akan putus ketika Syarifah tersebut mempunyai anak.

\footnotetext{
17Firjon, Wawancara, Desa Talang Sari Kab. Jember, 26 Desember 2019

${ }_{18}$ Muhammad, Wawancara, Desa Tegal Besar Kab. Jember, 21 November 2019
} 
Dari wawancara kepada para habaib penulis menyimpulkan bahwa seorang syarifah ketika menikah dengan seorang yang buka sayyid, itu biasanya, karena syarifah yang belum mengenali betul keutamaan dari duriyyah nabi Muhammad SAW, karena syarifah yang belum memahami bahwa di dalam dirinya terdapat sebuah kemuliaan. Yang perlu diperhatikan di kalangan Alawiyyin adalah mendidik anak-anak sejak dini agar mereka mengetahui dan mengenal apa itu sayyid, apa itu syarifah, dan apa itu kafa'ah dalam pernikahan. Penyimpangan yang terjadi di kalangan keluarga Habaib antara lain dikarenakan:

1. Orang tua yang bergaya modern.

2. Tidak mengetahui makna Dzuriyyat Nabi.

3. Kurang bergaul dalam lingkungan Habaib.

4. Terlanjur menikahkan puterinya dengan selain Habib.

5. Mendapat informasi dari sumber yang membenci Ba'alawi.

6. Ke-aku-an-nya yang berlebihan (egois)

7. Dan lain-lain.

Dengan garis besar apabila seorang Syarifah yang menikah dengan pria bukan Habib selain akan berdampak pada putusnya sebuah nasab yang mulia, nasab yang sambung pada Nabi Muhammad SAW, dan juga mempunyai dampak sosial yang sangat dalam yakni sebuah kecemburuan sosial.

\section{Kesimpulan}

Relefansi antara kafa'ah dengan keluarga sakinah sangatlah penting di kalangan Habaib, di mana diperlukan kafa'ah agar imbang menuju keluarga yang sakinah, yang apabila di antara keduanya tidak sesuai dengan sifat-sifat kafa'ah dikhawatirkan akan mengakibatkan sebuah keluarga tidak akan harmonis atau tidak sakinah. Meskipun di antara para Habib di Kabupaten Jember berbeda pendapat perihal kafa'ah, akan tetapi dengan adanya kafa'ah dalam pernikahan dimaksudkan sebagai upaya untuk menghindari terjadinya krisis rumah tangga dan perpecahan rumah tangga.

Pandangan Habaib terhadap perkawinan wanita syarifah dengan ahwal dalam upaya pembentukan keluarga sakinah. Seorang syarifah ketika menikah dengan seorang yang bukan Habib itu biasanya, karena syarifah yang belum mengenali betul keutamaan dari dzuriyyah Nabi Muhammad SAW, karena syarifah yang belum memahami bahwa di dalam dirinya terdapat sebuah kemuliaan. Syariat Islam selalu mengutamakan kemaslahatan dan menjaga kehormatannya. Syarifah yang menikah dengan pria bukan Habib selain dapat memutus nasabnya juga mempunyai dampak sosial.

\section{Daftar Pustaka}

\section{Buku}

Busriyanti, Figh Munakahat, Jember : STAIN Jember Press, 2013.

Sayyid Sabiq, Fiqih Sunnah 3, Jakarta: Pena Pundi Aksara, 2013.

Sugiyono, Metode Penelitian Kuantitatif, Kualitatif Dan RED, Bandung: Alfabet, 2009.

Rasjid Sulaiman, Figh Islam, Jakarta: Kurnia Esa, 1984.

Asrizal, "Relevansi Kafâ'ah terhadap Keharmonisan Rumah Tangga Perspektif Normatif dan Yuridis", Al-Ahwal, 1, Januari, 2015.

Sugiono, Metodologi Penelitian Kuantittif dan Kualitatif, Bandung: Alfa Beta, 2014. 


\section{Perundang-undangan}

Tim Citra Umbara, Undang-Undang no 1 Tahun 1974 tentang Perkawinan dan Kompilasi Hukum Islam, Bandung : CV Nuansa Auliya, 2015.

\section{Laman}

https://islam.nu.or.id/post/read/107374/menikah-adalah-fitrah-manusia 